\title{
Serum uric acid is an independent risk factor of worse mid- and long-term outcomes in patients with non-ST-segment elevation acute coronary syndromes
}

\author{
Maciej Dyrbuś ${ }^{1}$, Piotr Desperak ${ }^{2}$, Marta Pawełek ${ }^{1}$, \\ Mateusz Możdżeń ${ }^{1}$, Mariusz Gąsior ${ }^{2}$, Michał Hawranek ${ }^{2}$ \\ ${ }^{1}$ Student Scientific Society, $3^{\text {rd }}$ Department of Cardiology, School of Medical Sciences in Zabrze, \\ Medical University of Silesia, Katowice, Poland \\ ${ }^{2} 3^{\text {rd }}$ Department of Cardiology, School of Medical Sciences in Zabrze, \\ Medical University of Silesia, Katowice, Poland
}

\begin{abstract}
Background: The data on the association between serum uric acid (sUA) concentration and outcomes in patients with an acute coronary syndrome (ACS) are inconsistent and do not focus on patients with non-ST-segment elevation acute coronary syndromes (NSTE-ACS). The aim of this study was to analyze an association of $s U A$ concentration on admission and outcomes in those patients.

Methods: Data from the prospective, single-center registry of patients hospitalized due to NSTE-ACS from January 2006 to December 2016 were analyzed retrospectively. The population was divided into quartiles according to the baseline sUA. The primary outcome was the incidence of all-cause death, non-fatal myocardial infarction, stroke and ACS-driven revascularization at 36 months.

Results: Total of 2,824 patients with sUA measured on admission were included in this analysis with a median sUA of $352 \mu \mathrm{mol} / \mathrm{L}(5.92 \mathrm{mg} / \mathrm{dL})$. Patients with higher $s U A$ were older and more burdened with cardiovascular risk factors and history of coronary events. The prevalence of multivessel coronary artery disease and left main stenosis was significantly higher in patients with higher sUA. Elevated sUA concentration was associated with significantly worse short-, mid- and long-term outcomes. All-cause mortality was significantly higher in each analyzed period. In the multivariable analysis, sUA elevation was identified as an independent predictor of all-cause mortality at 12-month and 36-month follow-up. Conclusions: Elevated baseline sUA concentration was independently associated with worse mid-and long-term outcomes in patients with NSTE-ACS. Baseline sUA concentration could identify patients with NSTE-ACS at higher risk of more dismal prognosis. (Cardiol J)
\end{abstract}

Key words: acute coronary syndrome, coronary angiography, mortality, revascularization, uric acid

\section{Introduction}

Cardiovascular diseases (CVD) are a leading cause of worldwide premature mortality and morbidity, and it's estimated that the number of
Disability-Adjusted Life Years lost due to CVD will rise from 85 million in 1990 to 150 million in 2020 [1]. The most perilous manifestation of CVD is acute coronary syndromes (ACS). Despite the significant improvements in in-hospital, and post-

Address for correspondence: Michał Hawranek, MD, PhD, Silesian Center for Heart Diseases, ul. Szpitalna 2, 41-800 Zabrze, Poland, tel: +48 32 3733674, fax: +48 32 2732679, e-mail: mhawranek@poczta.fm

Received: 12.07.2021 Accepted: 13.08.2021 Early publication date: 1.12 .2021

This article is available in open access under Creative Common Attribution-Non-Commercial-No Derivatives 4.0 International (CC BY-NC-ND 4.0) license, allowing to download articles and share them with others as long as they credit the authors and the publisher, but without permission to change them in any way or use them commercially. 
-hospital care, outcomes in patients with ACS are still disadvantageous, thus necessitating a search for potential predictors of worsened short- and long-term prognosis after ACS.

For decades, an increased concentration of uric acid was perceived only as the underlying factor of gout, and a contributor in the formation of urinary tract stones. However, in the 1960s the connection between increased concentration of serum uric acid (sUA) and pathological findings in kidneys in patients with gout was found, followed by similar observations in asymptomatic patients with elevated sUA [2, 3]. Wider evidence confirming connections between hyperuricemia and hypertension was building, thus suggesting the long-term offshoots of elevated sUA on multiple human tissues [3]. According to the literature, rises in the sUA may trigger - or accelerate pathological mechanisms potentially contributing to an increased risk of major adverse cardiovascular events (MACE) development [4-6]. Recently, a few studies have investigated the predictive value of uric acid concentration in patients with ACS but the results were inconsistent, and the populations studied heterogenous [7-12]. Furthermore, there are no data focused specifically on patients presenting with non-ST-segment elevation acute coronary syndromes (NSTE-ACS) and further investigation in this field is required. The aim of this study is to assess the possible connection between the sUA concentration and outcomes of patients presenting with NSTE-ACS.

\section{Methods}

\section{Study design}

Data from the prospective, single-center registry of consecutive patients hospitalized for NSTE-ACS from January 2006 to December 2016 were analyzed retrospectively. Only patients with available data on sUA concentration were included in present analysis.

Patients were hospitalized in the tertiary cardiological center with cardiac surgery department and 24 hour/day catheterization duty. The management of NSTE-ACS was in accordance with contemporary recommendations of the European Society of Cardiology (ESC) [13-16]. All patients enrolled in the analysis had indications for the implementation of an invasive strategy. All interventional and therapeutic strategies were made at the discretion of the operating physician or heart team.

A blood sample was collected by venepuncture and drawn into a test tube containing ethylenedi- aminetetraacetic acid (EDTA). The samples were tested within $30 \mathrm{~min}$ of collection. All serum measurements, including sUA levels were determined using an automated Cobas Integra 800 device. As the sUA measurement does not belong to the standard laboratory biomarkers measured on admission in all patients with NSTE-ACS in the present facility, the decision to measure sUA was made entirely by the cardiologist in charge. The first sUA value measured during hospitalization was adopted into the study, and the vast majority of patients with sUA measurement available for analysis had it analyzed from the first blood sample drawn upon admission. Among 4,203 consecutive patients included in the registry, 2,824 had baseline sUA measured upon admission. The study population was divided by quartiles of the sUA value. The rationale for such an approach was that this was the first such study performed in patients specifically with NSTE-ACS and hence, the reference values of sUA in this population had not been established so far. Moreover, the reference ranges for the other conditions influencing sUA levels might not be appropriate for patients with NSTE-ACS. Finally, due to low sensitivity and specificity of receiver operating characteristic curves it was decided to assume the division of the population into quartiles.

The demographic, baseline clinical, and angiographic data collected during hospitalization were obtained from the institutional electronic database. The angiographic parameters were recorded on the basis of a visual assessment by two experienced interventional cardiologists. The follow-up data with accompanying exact dates of death, myocardial infarction (MI), stroke and ACS-driven revascularization were obtained from the official National Health Fund records.

This study was granted permission by the Institutional Review Board and University Bioethics Committee and is in accordance with the ethical standards of the 1964 Declaration of Helsinki. Due to the retrospective nature of this study, no additional patient consent was required.

\section{Primary outcome measure}

The primary outcome measure was the incidence of: (1) all-cause death, (2) non-fatal MI, (3) stroke and (4) ACS-driven revascularization at 36 months after initial hospitalization. The non-fatal MI was defined as an ischemic event that met contemporary Universal Definition of MI criteria and was clinically separate from the baseline ACS at the time of admission [13]. Periprocedural non-fatal MI was defined according to the criteria stated in 
the Universal Definition of MI. Stroke was defined as an ischemic event that was in accordance with the European Stroke Organization guidelines [17]. ACS-driven revascularization was defined as an unplanned percutaneous coronary intervention (PCI) or coronary artery bypass grafting (CABG) of a previously revascularized coronary artery, which had to be performed as an urgent procedure due to an ACS. In-hospital and 30-day outcomes are considered as short-term, 12-month outcomes as mid-term and 36-month outcomes as long-term follow-up. All adverse events in the short- and long-term follow-up have been validated.

\section{Statistical analyses}

The statistical analysis included the comparison of baseline clinical, angiographic, and procedural characteristics, and the in-hospital and 30-day, 12-month, and 36-month adverse events. The continuous variables were summarized using an arithmetic mean with standard deviation for data following normal distribution or a median with quartile 1 and 3 for non-normal distribution. The analyzed categorical variables were presented using frequency tables for both absolute numbers and percentages. Following the literature findings, which indicate that there is an organized association between consecutive groups studied and adverse cardiovascular events, the statistical tests for trends were utilized. The significance of the trends of variables in the study groups was evaluated using the Cochran-Armitage test for parametric variables and the Jonckheere-Terpstra test for continuous variables. The 36-month all-cause death, stroke, non-fatal MI and ACS-driven revascularization were analyzed using the Kaplan-Meier method with log-rank test for all patients.

The effects of the evaluated parameters on the 36-month incidence of adverse events were assessed using the Cox proportional regression model ( $\mathrm{p}<0.1$ for inclusion in the model, $\mathrm{p}<0.05$ for remaining in the model) with the results expressed as hazard ratios and 95\% confidence intervals. All investigated clinical and angiographic parameters that were statistically significant were included in the unifactorial analysis after the exclusion of co-dependent variables in the correlation analysis. A two-sided $\mathrm{p}$ value $\leq 0.05$ was considered significant. The Jonckheere-Terpstra test was calculated using the SPSS ver. 17.0.1 (SPSS, Inc., Chicago, Illinois) software, the Cochran-Armitage test was calculated with the MedCalc (MedCalc Software, Mariakerke, Belgium) software and all other statistical analyzes were performed using the
STATISTICA 10 (StatSoft Inc., Tulsa, Oklahoma) software.

\section{Results}

\section{Baseline characteristics}

The median sUA concentration was 352 $\mu \mathrm{mol} / \mathrm{L}(5.92 \mathrm{mg} / \mathrm{dL})$ and the quartiles of uric acid concentration were as follows: quartile $1:<289$ $\mu \mathrm{mol} / \mathrm{L}(<4.86 \mathrm{mg} / \mathrm{dL})$; quartile $2: 289-352 \mu \mathrm{mol} / \mathrm{L}$ (4.86-5.92 mg/dL); quartile 3: 353-431 $\mu \mathrm{mol} / \mathrm{L}$ $(5.93-7.24 \mathrm{mg} / \mathrm{dL})$; and quartile $4:>431 \mu \mathrm{mol} / \mathrm{L}$ $(>7.24 \mathrm{mg} / \mathrm{dL})$. Baseline demographic and clinical characteristics are presented in Table 1 . There was a significant trend for higher age, percentage of male gender and more prolific history of MI with higher baseline sUA. Moreover, a significant trend towards higher occurrence of diabetes, chronic obstructive pulmonary disease and hypertension was observed. Patients with higher sUA were also more often assigned to the higher Killip classes, had a significantly higher Global Registry of Acute Coronary Events (GRACE) risk score and serum creatinine levels than patients with lower sUA concentration, but significantly lower left ventricular ejection fraction (LVEF).

\section{Angiographic and procedural characteristics}

The angiographic and procedural characteristics of the studied population are presented in Table 2. Single-vessel disease occurred more frequently in patients with lower sUA concentration, while there was a trend for more frequent multi-vessel disease and left main artery disease in patients with higher sUA. It is worth noting that the occurrence of chronically totally occluded (CTO) arteries was significantly higher in patients with higher sUA.

No significant trends were observed as far as the rates of $\mathrm{PCI}$ or $\mathrm{CABG}$ revascularization were concerned. However, the distribution of the arteries revascularized percutaneously differed slightly according to sUA. The left main was treated significantly more frequently, and the left circumflex artery significantly less frequently with increasing sUA. Numerical but insignificant differences were observed with regard to the other arteries and bypass grafts.

There were no differences in direct outcomes of the PCI, and the periprocedural success rate was comparable between the quartiles. The pharmacotherapy administered at discharge did slightly differ between the quartiles, including significant differences in the administration of antiplatelet therapy, oral anticoagulants, angiotensin-convert- 
Table 1. Baseline characteristics of the study population depending on the quartile of uric acid concentration on admission

\begin{tabular}{|c|c|c|c|c|c|}
\hline \multirow[t]{2}{*}{ Variable } & \multicolumn{4}{|c|}{ Uric acid value on admission $[\mu \mathrm{mol} / \mathrm{L}](\mathrm{n}=2,824)$} & \multirow{2}{*}{$\begin{array}{c}P \\
\text { for } \\
\text { trend }\end{array}$} \\
\hline & $\begin{array}{c}<289 \\
(n=706)\end{array}$ & $\begin{array}{l}289-352 \\
(n=706)\end{array}$ & $\begin{array}{l}353-431 \\
(n=707)\end{array}$ & $\begin{array}{c}>431 \\
(n=705)\end{array}$ & \\
\hline $\begin{array}{l}\text { Age [years], } \\
\text { mean } \pm S D(n / N)\end{array}$ & $\begin{array}{l}64.7 \pm 10.8 \\
(706 / 706)\end{array}$ & $\begin{array}{l}64.8 \pm 10.9 \\
(706 / 706)\end{array}$ & $\begin{array}{l}66.5 \pm 10.4 \\
(707 / 707)\end{array}$ & $\begin{array}{l}68.5 \pm 10.4 \\
(705 / 705)\end{array}$ & $<0.0001$ \\
\hline Males, \% (n/N) & $53.0(374 / 706)$ & $66.0(466 / 706)$ & $72.1(510 / 707)$ & $70.1(494 / 705)$ & $<0.0001$ \\
\hline NSTEMI diagnosis, \% (n/N) & $57.8(408 / 706)$ & $55.1(389 / 706)$ & $57.9(409 / 707)$ & $59.7(421 / 705)$ & 0.31 \\
\hline Arterial hypertension, \% (n/N) & $79.4(559 / 704)$ & $81.8(576 / 704)$ & $82.2(579 / 706)$ & $86.7(609 / 703)$ & 0.0006 \\
\hline Prior $\mathrm{MI}, \%(\mathrm{n} / \mathrm{N})$ & $34.4(242 / 703)$ & $37.0(260 / 702)$ & $41.0(288 / 703)$ & $44.4(311 / 700)$ & $<0.0001$ \\
\hline Prior $\mathrm{PCl}, \%(\mathrm{n} / \mathrm{N})$ & $39.9(281 / 704)$ & $39.7(279 / 704)$ & $42.9(302 / 704)$ & $43.1(303 / 703)$ & 0.12 \\
\hline Prior CABG, \% (n/N) & $15.0(106 / 706)$ & $13.3(94 / 706)$ & $15.8(112 / 707)$ & $18.0(127 / 705)$ & 0.059 \\
\hline Atrial fibrillation, \% (n/N) & $11.6(82 / 706)$ & $13.0(92 / 706)$ & $15.1(107 / 707)$ & $20.9(147 / 705)$ & $<0.0001$ \\
\hline $\begin{array}{l}\text { Peripheral artery disease, } \\
\%(n / N)\end{array}$ & $11.8(83 / 704)$ & $11.6(81 / 701)$ & $13.4(94 / 701)$ & $16.8(118 / 702)$ & 0.0033 \\
\hline Prior stroke, \% (n/N) & $5.4(38 / 706)$ & $6.1(43 / 706)$ & $5.8(41 / 707)$ & $7.7(54 / 705)$ & 0.11 \\
\hline Diabetes mellitus, $\%(\mathrm{n} / \mathrm{N})$ & $35.4(249 / 704)$ & $39.2(275 / 702)$ & $39.7(287 / 701)$ & $50.4(354 / 702)$ & $<0.0001$ \\
\hline $\begin{array}{l}\text { Requiring insulin treatment, } \\
\%(n / N)\end{array}$ & $12.5(88 / 702)$ & $12.2(85 / 697)$ & $14.7(103 / 701)$ & $21.9(153 / 699)$ & $<0.0001$ \\
\hline $\begin{array}{l}\text { Hypercholesterolemia, } \\
\%(n / N)\end{array}$ & $73.5(518 / 705)$ & $75.7(534 / 705)$ & $76.9(543 / 706)$ & $78.3(552 / 705)$ & 0.030 \\
\hline COPD, \% (n/N) & $3.8(27 / 704)$ & $4.4(31 / 701)$ & $7.0(49 / 701)$ & $9.4(66 / 702)$ & $<0.0001$ \\
\hline $\begin{array}{l}\text { History of cigarette smoking, } \\
\%(n / N)\end{array}$ & $42.2(296 / 702)$ & $44.1(308 / 699)$ & $43.0(302 / 703)$ & $41.5(291 / 701)$ & 0.71 \\
\hline Familial history of $\mathrm{MI}, \%(\mathrm{n} / \mathrm{N})$ & $25.1(176 / 702)$ & $20.7(144 / 697)$ & $26.4(185 / 701)$ & $21.0(147 / 699)$ & 0.37 \\
\hline Killip III*, \% (n/N) & $1.1(8 / 701)$ & $0.6(4 / 697)$ & $1.3(9 / 700)$ & $3.3(23 / 693)$ & 0.0006 \\
\hline Killip IV* $\%$ (n/N) & $0.4(3 / 701)$ & $0.4(3 / 697)$ & $0.4(3 / 700)$ & $2.1(12 / 693)$ & 0.0078 \\
\hline $\begin{array}{l}\mathrm{BMI}^{*}\left[\mathrm{~kg} / \mathrm{m}^{2}\right], \text { median; } \\
\mathrm{Q} 1-\mathrm{Q} 3(\mathrm{n} / \mathrm{N})\end{array}$ & $\begin{array}{l}27.2 ; 24.3-29.7 \\
\quad(453 / 706)\end{array}$ & $\begin{array}{l}28.2 ; 25.2-31.1 \\
(466 / 706)\end{array}$ & $\begin{array}{l}29.1 ; 25.8-31.6 \\
(467 / 707)\end{array}$ & $\begin{array}{c}29.8 ; 26.2-32.7 \\
(463 / 705)\end{array}$ & $<0.0001$ \\
\hline $\begin{array}{l}\text { Uric acid* }[\mu \mathrm{mol} / \mathrm{L}], \text { median; } \\
\text { Q1-Q3 }(\mathrm{n} / \mathrm{N})\end{array}$ & $\begin{array}{l}249 ; 221-272 \\
(706 / 706)\end{array}$ & $\begin{array}{l}321 ; 306-337 \\
(706 / 706)\end{array}$ & $\begin{array}{l}388 ; 370-408 \\
(707 / 707)\end{array}$ & $\begin{array}{l}497 ; 462-558 \\
(705 / 705)\end{array}$ & $<0.0001$ \\
\hline $\begin{array}{l}\text { Glucose }{ }^{*}[\mathrm{mmol} / \mathrm{L}], \text { median; } \\
\text { Q1-Q3 }(\mathrm{n} / \mathrm{N})\end{array}$ & $\begin{array}{l}6.1 ; 5.3-8.0 \\
(688 / 706)\end{array}$ & $\begin{array}{l}6.2 ; 5.4-8.0 \\
(691 / 706)\end{array}$ & $\begin{array}{l}6.3 ; 5.5-7.9 \\
(690 / 707)\end{array}$ & $\begin{array}{l}6.8 ; 5.7-9.0 \\
(699 / 705)\end{array}$ & $<0.0001$ \\
\hline $\begin{array}{l}\text { Serum creatinine }{ }^{*}[\mu \mathrm{mol} / \mathrm{L}] \\
\text { median; Q1-Q3 }(\mathrm{n} / \mathrm{N})\end{array}$ & $\begin{array}{l}72 ; 60-85 \\
(704 / 706)\end{array}$ & $\begin{array}{l}78 ; 68-91 \\
(706 / 706)\end{array}$ & $\begin{array}{l}86 ; 74-103 \\
(706 / 707)\end{array}$ & $\begin{array}{c}104 ; 85-133 \\
(705 / 705)\end{array}$ & $<0.0001$ \\
\hline $\begin{array}{l}\text { eGFR* }\left[\mathrm{mL} / \mathrm{min} / 1.73 \mathrm{~m}^{2}\right] \\
\text { median; } \mathrm{Q} 1-\mathrm{Q} 3(\mathrm{n} / \mathrm{N})\end{array}$ & $\begin{array}{l}90 ; 74-107 \\
(706 / 706)\end{array}$ & $\begin{array}{l}84 ; 69-98 \\
(705 / 706)\end{array}$ & $\begin{array}{l}77 ; 61-93 \\
(706 / 707)\end{array}$ & $\begin{array}{l}61 ; 45-77 \\
(705 / 705)\end{array}$ & $<0.0001$ \\
\hline $\begin{array}{l}\text { GRACE risk score [points] } \\
\text { mean } \pm S D(n / N)\end{array}$ & $\begin{array}{l}113 \pm 28 \\
(706 / 706)\end{array}$ & $\begin{array}{l}113 \pm 29 \\
(706 / 706)\end{array}$ & $\begin{array}{l}118 \pm 28 \\
(707 / 707)\end{array}$ & $\begin{array}{l}127 \pm 31 \\
(705 / 705)\end{array}$ & $<0.0001$ \\
\hline LVEF* $\left.^{*} \%\right]$ mean \pm SD $(\mathrm{n} / \mathrm{N})$ & $\begin{array}{l}47.3 \pm 9.7 \\
(679 / 706)\end{array}$ & $\begin{array}{l}45.8 \pm 10.0 \\
(676 / 706)\end{array}$ & $\begin{array}{c}44.6 \pm 11.1 \\
(684 / / 707)\end{array}$ & $\begin{array}{c}41.1 \pm 12.3 \\
(681 / 705)\end{array}$ & $<0.0001$ \\
\hline
\end{tabular}

*On admission; $\mathrm{BMI}$ - body mass index; CABG — coronary-artery bypass grafting; COPD — chronic obstructive pulmonary disease;

eGFR - estimated glomerular filtration rate; LVEF — left ventricular ejection fraction; MI — myocardial infarction; NSTEMI - non-ST-segment elevation myocardial infarction; $\mathrm{PCI}$ - percutaneous coronary intervention; Q1-Q3 - quartile 1 and 3; SD — standard deviation

ing enzyme inhibitors, diuretics and allopurinol as presented in Table 3.

\section{Short-, mid- and long-term outcomes}

As described in Table 4, in-hospital outcomes differed significantly between the quartiles. There was a significant trend for higher in-hospital mortality with increasing sUA, which was 13 -fold higher in patients from the $4^{\text {th }}$ quartile, when compared with patients from the $1^{\text {st }}$ quartile. During hospitalization, no significant differences in the occurrence of non-fatal MI, target-vessel revascularization 
Table 2. Angiographic and procedural characteristics of the study population depending on the quartile of uric acid concentration on admission.

\begin{tabular}{|c|c|c|c|c|c|}
\hline \multirow[t]{2}{*}{ Variable } & \multicolumn{4}{|c|}{ Uric acid value on admission $[\mu \mathrm{mol} / \mathrm{L}](\mathrm{n}=2,824)$} & \multirow{2}{*}{$\begin{array}{c}P \\
\text { for } \\
\text { trend }\end{array}$} \\
\hline & $\begin{array}{c}<289 \\
(n=706)\end{array}$ & $\begin{array}{l}289-352 \\
(n=706)\end{array}$ & $\begin{array}{l}353 / 431 \\
(n=707)\end{array}$ & $\begin{array}{c}>431 \\
(n=705)\end{array}$ & \\
\hline \multicolumn{6}{|l|}{ Coronary angiography } \\
\hline Radial access, \% (n/N) & $25.8(182 / 706)$ & $27.3(193 / 706)$ & $26.7(189 / 707)$ & $27.8(196 / 705)$ & 0.52 \\
\hline No significant stenosis, \% (n/N) & $9.1(64 / 706)$ & $9.1(64 / 706)$ & $6.9(49 / 707)$ & $8.4(59 / 705)$ & 0.36 \\
\hline 1-vessel CAD, \% (n/N) & $42.9(303 / 706)$ & $38.8(274 / 706)$ & $39.0(276 / 707)$ & $31.8(224 / 705)$ & $<0.0001$ \\
\hline 2-vessel CAD, \% (n/N) & $26.4(186 / 706)$ & $29.0(205 / 706)$ & $34.8(246 / 707)$ & $31.8(224 / 705)$ & 0.0044 \\
\hline 3-vessel CAD, \% (n/N) & $18.1(128 / 706)$ & $20.5(145 / 706)$ & $18.0(127 / 707)$ & $27.5(194 / 705)$ & 0.0002 \\
\hline LM CAD, \% (n/N) & $8.4(59 / 706)$ & $9.4(66 / 706)$ & $9.6(68 / 707)$ & $12.9(91 / 705)$ & 0.006 \\
\hline CTO of non-culprit artery, \% (n/N) & $19.5(118 / 605)$ & $22.7(141 / 620)$ & $26.1(157 / 602)$ & $36.8(217 / 590)$ & $<0.0001$ \\
\hline Revascularization, \% (n/N) & $80.3(567 / 706)$ & $81.6(576 / 706)$ & $84.3(596 / 707)$ & $83.7(590 / 705)$ & 0.045 \\
\hline $\mathrm{PCl}, \%(\mathrm{n} / \mathrm{N})$ & $78.2(552 / 706)$ & $78.1(551 / 706)$ & $80.6(570 / 707)$ & $80.9(570 / 705)$ & 0.12 \\
\hline LM, \% (n/N) & $3.6(20 / 552)$ & $3.6(20 / 551)$ & $4.0(43 / 570)$ & $7.5(43 / 570)$ & 0.0023 \\
\hline LAD, \% (n/N) & $34.8(192 / 552)$ & $34.1(188 / 551)$ & $33.3(190 / 570)$ & $31.8(181 / 570)$ & 0.26 \\
\hline $\mathrm{Cx}, \%(\mathrm{n} / \mathrm{N})$ & $28.6(158 / 552)$ & $29.6(163 / 551)$ & $28.8(164 / 570)$ & $23.2(132 / 570)$ & 0.040 \\
\hline $\mathrm{RCA}, \%(\mathrm{n} / \mathrm{N})$ & $29.9(165 / 552)$ & $28.7(158 / 551)$ & $29.3(167 / 570)$ & $32 / 3(184 / 570)$ & 0.36 \\
\hline Bypass, \% (n/N) & $3.1(17 / 552)$ & $4.0(22 / 551)$ & $4.6(26 / 570)$ & $5.3(30 / 570)$ & 0.061 \\
\hline $\begin{array}{l}\text { Baseline TIMI flow grade } 0-1 \text {, } \\
\%(n / N)\end{array}$ & $20.8(115 / 552)$ & $23.4(129 / 551)$ & $20.4(116 / 570)$ & $18.3(104 / 570)$ & 0.15 \\
\hline Stent implantation, \% (n/N) & $87.8(479 / 552)$ & $87.1(480 / 551)$ & $88.6(505 / 570)$ & $86.1(491 / 570)$ & 0.94 \\
\hline Drug eluting stent, $\%(n / N)$ & $62.2(298 / 479)$ & $60.6(291 / 480)$ & $64.0(323 / 505)$ & $62.5(307 / 491)$ & 0.66 \\
\hline $\begin{array}{l}\text { Procedural glycoprotein Ilb/llla } \\
\text { inhibitor, \% (n/N) }\end{array}$ & $9.2(51 / 552)$ & $11.6(64 / 551)$ & $11.2(64 / 570)$ & $13.5(77 / 570)$ & 0.039 \\
\hline $\begin{array}{l}\text { Final TIMI flow grade } 3 \text { after } \mathrm{PCl} \text {, } \\
\%(\mathrm{n} / \mathrm{N})\end{array}$ & $95.1(525 / 552)$ & $94.7(522 / 551)$ & $94.4(538 / 570)$ & $92.1(525 / 570)$ & 0.035 \\
\hline Procedural success of $\mathrm{PCl},(\mathrm{n} / \mathrm{N})$ & $93.3(515 / 552)$ & $92.2(508 / 551)$ & $92.3(526 / 570)$ & $89.1(508 / 570)$ & 0.017 \\
\hline CABG, \% (n/N) & $4.4(31 / 706)$ & $6.4(45 / 706)$ & $5.2(37 / 707)$ & $5.1(36 / 705)$ & 0.79 \\
\hline
\end{tabular}

CAD — coronary artery disease; $C x$ - circumflex artery; LAD — left anterior descending artery; LM — left main; LVEF — left ventricular ejection fraction; $\mathrm{PCl}$ - percutaneous coronary intervention; RCA - right coronary artery; CTO - chronic total occlusion; TIMI - thrombolysis in myocardial infarction; serum uric acid concentration conversion rate: $1 \mu \mathrm{mol}=0.0168 \mathrm{mg} / \mathrm{dL}$

(TVR) and stroke were observed between the subgroups. However, patients from the $3^{\text {rd }}$ and the $4^{\text {th }}$ quartile, significantly more frequently developed cardiogenic shock and pulmonary edema. Their hospital stay was also significantly longer than that of patients with lower sUA.

The longer-term mortality was strictly associated with sUA concentration. At day 30 , the trend for higher mortality in patients with higher sUA persisted, as the risk of death among patients with sUA $>431 \mu \mathrm{mol} / \mathrm{L}$ ( $>7.24 \mathrm{mg} / \mathrm{dL}$ ) was almost 4 -fold higher than among patients from the $1^{\text {st }}$ quartile. All-cause mortality was consistently higher in patients from the $4^{\text {th }}$ quartile reaching $31.7 \%$ at 36-month follow-up, than in patients from the $1^{\text {st }}$ quartile (9.7\%). Although in the 30-day follow-up, patients from the $3^{\text {rd }}$ and $4^{\text {th }}$ quartiles significantly more frequently suffered from non-fatal MI, no such difference was observed in the longer follow up. In contrary, despite no significant differences in stroke rate in the first 12 months, patients with the highest baseline sUA levels more frequently developed stroke in the second and third year of followup, reaching 5.5\% after 36 months. No significant differences in the occurrence of ACS-driven revascularization were observed in any analyzed period. Figure 1A-D depicts the Kaplan-Meier curves for all-cause death (Fig. 1A), non-fatal MI (Fig. 1B), ACS-driven revascularization (Fig. 1C) and stroke (Fig. 1D) occurrence in all four quartiles. 
Table 3. Pharmacotherapy at discharge.

\begin{tabular}{|c|c|c|c|c|c|}
\hline \multirow[t]{2}{*}{ Variable } & \multicolumn{4}{|c|}{ Uric acid value on admission $[\mu \mathrm{mol} / L](n=2,824)$} & \multirow{2}{*}{$\begin{array}{c}\text { P } \\
\text { for } \\
\text { trend }\end{array}$} \\
\hline & $\begin{array}{c}<289 \\
(n=706)\end{array}$ & $\begin{array}{c}289-352 \\
(n=706)\end{array}$ & $\begin{array}{c}353 / 431 \\
(n=707)\end{array}$ & $\begin{array}{c}>431 \\
(n=705)\end{array}$ & \\
\hline \multicolumn{6}{|l|}{ Pharmacotherapy at discharge } \\
\hline Acetylsalicylic acid, \% (n/N) & $92.8(647 / 697)$ & $92.6(648 / 700)$ & $92.7(640 / 690)$ & $87.7(589 / 672)$ & 0.0014 \\
\hline PY12 inhibitors, \% (n/N) & $82.6(576 / 697)$ & $83.3(583 / 700)$ & $84.9(586 / 690)$ & $79.2(532 / 672)$ & 0.19 \\
\hline Oral anticoagulants, \% (n/N) & $6.6(46 / 697)$ & $8.9(62 / 700)$ & $9.1(63 / 690)$ & $12.7(85 / 672)$ & 0.0002 \\
\hline Beta-blocker, \% (n/N) & $86.7(604 / 697)$ & $87.9(615 / 700)$ & $89.0(614 / 690)$ & $84.7(569 / 672)$ & 0.42 \\
\hline $\mathrm{ASA}, \%(\mathrm{n} / \mathrm{N})$ & $81.9(571 / 697)$ & $82.7(579 / 700)$ & $82.7(571 / 690)$ & $77.2(519 / 672)$ & 0.038 \\
\hline Statin, \% (n/N) & $93.9(646 / 688)$ & $95.1(657 / 691)$ & $93.7(635 / 678)$ & $91.0(596 / 655)$ & 0.019 \\
\hline Nitrate, \% (n/N) & $25.5(178 / 697)$ & $29.1(204 / 700)$ & $27.8(192 / 690)$ & $30.8(207 / 672)$ & 0.060 \\
\hline Diuretic, \% (n/N) & $30.7(214 / 697)$ & $33.7(236 / 700)$ & $40.6(280 / 690)$ & $54.8(368 / 672)$ & $<0.0001$ \\
\hline Allopurinol, \% (n/N) & $5.2(36 / 697)$ & $6.1(43 / 700)$ & $10.1(70 / 690)$ & $35.0(235 / 672)$ & $<0.0001$ \\
\hline
\end{tabular}

ASA - angiotensin-converting enzyme inhibitor; serum uric acid concentration conversion rate: $1 \mu \mathrm{mol}=0.0168 \mathrm{mg} / \mathrm{dL}$

In the multivariable analysis, revascularization was the only independent variable significantly decreasing the risk of 12 -month and 36 -month mortality (Fig. 2, Suppl. Fig. 1). In contrary, the independent risk factors of all-cause mortality in both 12 -month and 36-month follow-up were elevated creatinine, advanced age, reduction of hemoglobin levels, decreased LVEF, presence of ST-segment deviation and of multivessel coronary artery disease (CAD). According to multivariable analysis, each increase in the concentration of sUA by $10 \mu \mathrm{mol} / \mathrm{L}$ was associated with a respectively $4 \%$ and $2 \%$ higher hazard of death after 12 and 36 months. Type II diabetes was the remaining independent risk factor of 36 -month mortality.

\section{Discussion}

The major findings of the present study can be summarized as follows: 1) The clinical and angiographic profile of patients with NSTE-ACS differs in association with the sUA concentration; 2) Elevated sUA is associated with worse short-, mid- and long-term outcomes in patients with NSTE-ACS; 3) Patients with elevated sUA are at higher risk of in-hospital, 30-day, 12-month and 36 -month death and stroke at 36 months than patients with lower sUA levels; 4) There are no major differences in the occurrence of non-fatal MI and ACS-driven revascularization in short-, mid- and long-term follow-up.

It should be mentioned that, according to available research, this is the first retrospective study evaluating the influence of hyperuricemia on outcomes specifically in a large cohort of patients with NSTE-ACS.

Although the mechanisms linking hyperuricemia and the development of CVD still require analysis, elevated sUA has been identified as an independent risk factor for the development, and advancement of multiple cardiovascular risk factors and comorbidities. Recent findings indicate its contribution not only in the development of hypertension, but also in the components of metabolic syndrome, obesity, diabetes and chronic kidney disease [18-21]. There is also evidence associating the presence, significance and extension of CAD with higher levels of sUA $[22,23]$. The mechanisms of those associations probably involve intracellular and intravascular activation of proinflammatory pathways, along with the modification of local immunological processes, endothelial dysfunction and destabilization of the physiological vasoconstriction-vasodilation balance $[24,25]$.

Moreover, based on the intravascular imaging techniques, elevated sUA is associated with changes in the contents of the atherosclerotic plaques, mostly regarding the larger dimensions of the lipidic plaque, higher lipidic and lower fibrotic content, with higher occurrence of plaque ruptures and red thrombi than in subjects with lower sUA [26-29]. Finally, the plaques in patients with elevated sUA levels have a significantly lower minimum vessel lumen area demonstrating a more significant extent of CAD. 
Table 4. Short-, mid- and long-term outcomes of the study population depending on a quartile of an uric acid value on admission.

\begin{tabular}{|c|c|c|c|c|c|}
\hline \multirow[t]{2}{*}{ Variable } & \multicolumn{4}{|c|}{ Uric acid value on admission $[\mu \mathrm{mol} / \mathrm{L}](\mathrm{n}=2,824)$} & \multirow{2}{*}{$\begin{array}{c}\text { P } \\
\text { for } \\
\text { trend }\end{array}$} \\
\hline & $\begin{array}{c}<289 \\
(n=706)\end{array}$ & $\begin{array}{l}289-352 \\
(n=706)\end{array}$ & $\begin{array}{c}353 / 431 \\
(n=707)\end{array}$ & $\begin{array}{c}>431 \\
(n=705)\end{array}$ & \\
\hline \multicolumn{6}{|l|}{ In-hospital outcomes } \\
\hline Death, \% (n/N) & $0.3(2 / 706)$ & $0.7(5 / 706)$ & $2.1(15 / 707)$ & $3.6(25 / 705)$ & $<0.0001$ \\
\hline Non-fatal MI, \% (n/N) & $1.1(8 / 706)$ & $0.6(4 / 706)$ & $1.3(9 / 707)$ & $1.4(10 / 705)$ & 0.37 \\
\hline TVR, \% $(n / N)$ & $1.4(10 / 706)$ & $1.6(11 / 706)$ & $1.3(9 / 707)$ & $1.8(13 / 705)$ & 0.63 \\
\hline Stroke, \% (n/N) & $0.6(4 / 706)$ & $0.3(2 / 706)$ & $0.3(2 / 707)$ & $0.9(6 / 705)$ & 0.47 \\
\hline Cardiogenic shock, \% (n/N) & $1.0(7 / 706)$ & $1.4(10 / 706)$ & $1.7(12 / 707)$ & $4.8(34 / 705)$ & $<0.0001$ \\
\hline Pulmonary edema, \% (n/N) & $1.8(13 / 706)$ & $2.0(14 / 706)$ & $3.7(26 / 707)$ & $8.9(63 / 705)$ & $<0.0001$ \\
\hline Major bleeding, \% (n/N) & $3.5(25 / 706)$ & $3.8(27 / 706)$ & $3.4(24 / 707)$ & $6.0(42 / 705)$ & 0.043 \\
\hline $\begin{array}{l}\text { Hospital stay [days] median; } \\
\text { Q1-Q3 (n/N) }\end{array}$ & $\begin{array}{c}4 ; 3-6 \\
(706 / 706)\end{array}$ & $\begin{array}{c}5 ; 3-7 \\
(706 / 706)\end{array}$ & $\begin{array}{c}5 ; 3-6 \\
(707 / 707)\end{array}$ & $\begin{array}{c}6 ; 3-8 \\
(705 / 705)\end{array}$ & $<0.0001$ \\
\hline \multicolumn{6}{|l|}{ Long-term outcomes } \\
\hline \multicolumn{6}{|l|}{ 30-days } \\
\hline Death, \% (n/N) & $1.4(10 / 706)$ & $1.4(10 / 706)$ & $3.4(24 / 707)$ & $5.0(35 / 705)$ & $<0.0001$ \\
\hline Non-fatal MI, \% (n/N) & $2.1(15 / 706)$ & $0.9(6 / 706)$ & $3.0(21 / 707)$ & $2.8(20 / 705)$ & 0.084 \\
\hline $\begin{array}{l}\text { ACS-driven revascularization, } \\
\%(n / N)\end{array}$ & $2.4(17 / 706)$ & $2.3(16 / 706)$ & $2.6(18 / 707)$ & $3.0(21 / 705)$ & 0.45 \\
\hline Stroke, $\%(n / N)$ & $0.9(6 / 706)$ & $0.3(2 / 706)$ & $0.3(2 / 707)$ & $1.1(8 / 705)$ & 0.53 \\
\hline \multicolumn{6}{|l|}{ 12-month } \\
\hline Death, \% (n/N) & $5.7(40 / 706)$ & $5.5(39 / 706)$ & $8.6(61 / 707)$ & $16.7(118 / 705)$ & $<0.0001$ \\
\hline Non-fatal Ml, \% (n/N) & $7.8(55 / 706)$ & $6.4(45 / 706)$ & $8.9(63 / 707)$ & $9.5(76 / 705)$ & 0.096 \\
\hline $\begin{array}{l}\text { ACS-driven revascularization, } \\
\%(n / N)\end{array}$ & $11.6(82 / 706)$ & $8.5(60 / 706)$ & $8.2(58 / 707)$ & $9.9(70 / 705)$ & 0.28 \\
\hline Stroke, \% (n/N) & $1.7(12 / 706)$ & $1.0(7 / 706)$ & $1.6(11 / 707)$ & $2.3(16 / 705)$ & 0.12 \\
\hline \multicolumn{6}{|l|}{ 36-month } \\
\hline Death, \% (n/N) & $9.7(51 / 527)$ & $13.4(69 / 514)$ & $19.4(101 / 522)$ & $31.7(161 / 508)$ & $<0.0001$ \\
\hline Non-fatal MI, \% (n/N) & $11.8(62 / 527)$ & $11.3(58 / 514)$ & $15.3(80 / 522)$ & $15.0(76 / 508)$ & 0.041 \\
\hline $\begin{array}{l}\text { ACS-driven revascularization, } \\
\%(n / N)\end{array}$ & $15.6(82 / 527)$ & $15.2(78 / 514)$ & $16.3(85 / 522)$ & $14.4(73 / 508)$ & 0.74 \\
\hline Stroke, \% (n/N) & $2.3(12 / 527)$ & $2.9(15 / 514)$ & $3.8(20 / 522)$ & $5.5(28 / 508)$ & 0.004 \\
\hline
\end{tabular}

ACS - acute coronary syndrome; MI - myocardial infarction; Q1-Q3 - quartile 1 and 3; TVR - target-vessel revascularization serum uric acid concentration conversion rate: $1 \mu \mathrm{mol}=0.0168 \mathrm{mg} / \mathrm{dL}$

Differences in the clinical and angiographic profile

The studied population of 2,824 patients with NSTE-ACS significantly differed between the quartiles. Similar to previous studies, patients from two highest quartiles were significantly more burdened with cardiovascular risk factors, such as hypertension, diabetes and obesity. Hence, it appears that an elevation in the sUA concentration at baseline could be used to identify patients with NSTE-ACS in worse clinical condition and perform an initial risk stratification to define the subgroup with the most dismal prognosis.
The association of elevated sUA and CAD distribution is still a matter of debate. The results of the present study are consistent with those of the study by Ndrepepa et al. [9], who similarly divided a population of 5,124 patients admitted with STEMI and NSTE-ACS into quartiles depending on their baseline sUA concentration. In both studies, patients from the $4^{\text {th }}$ quartile presented significantly more progressed CAD, with the number of vessels affected rising with sUA concentration. In contrary to the results of the current study, in the analysis by Kojima et al. [30], there were no significant differences between the quartiles and the highest 


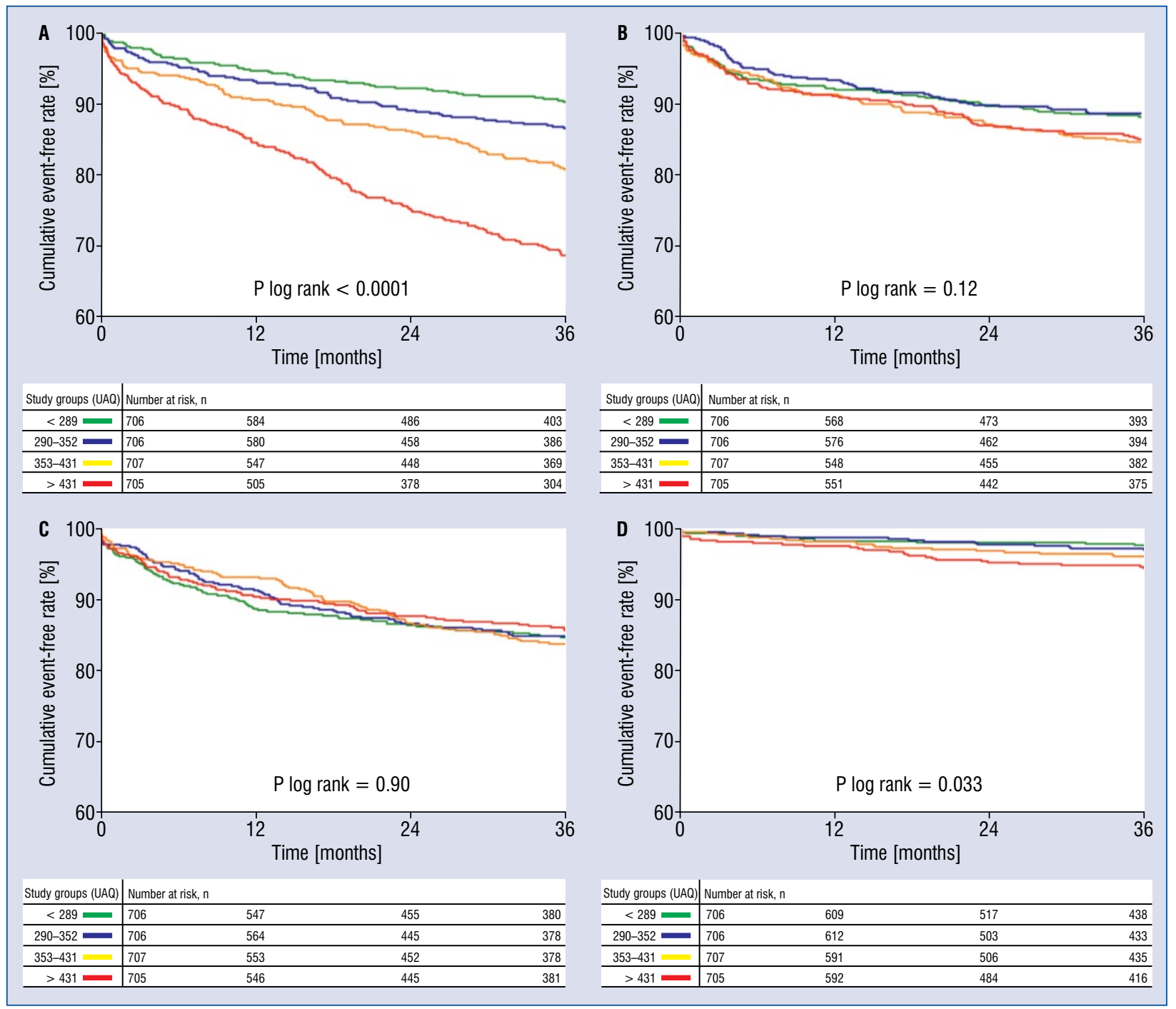

Figure 1. Kaplan-Meier curves for all-cause death (A), non-fatal myocardial infarction (B), acute coronary syndromedriven revascularization (C) and stroke (D) occurrence in all four quartiles; UAQ — urea acid quartiles.

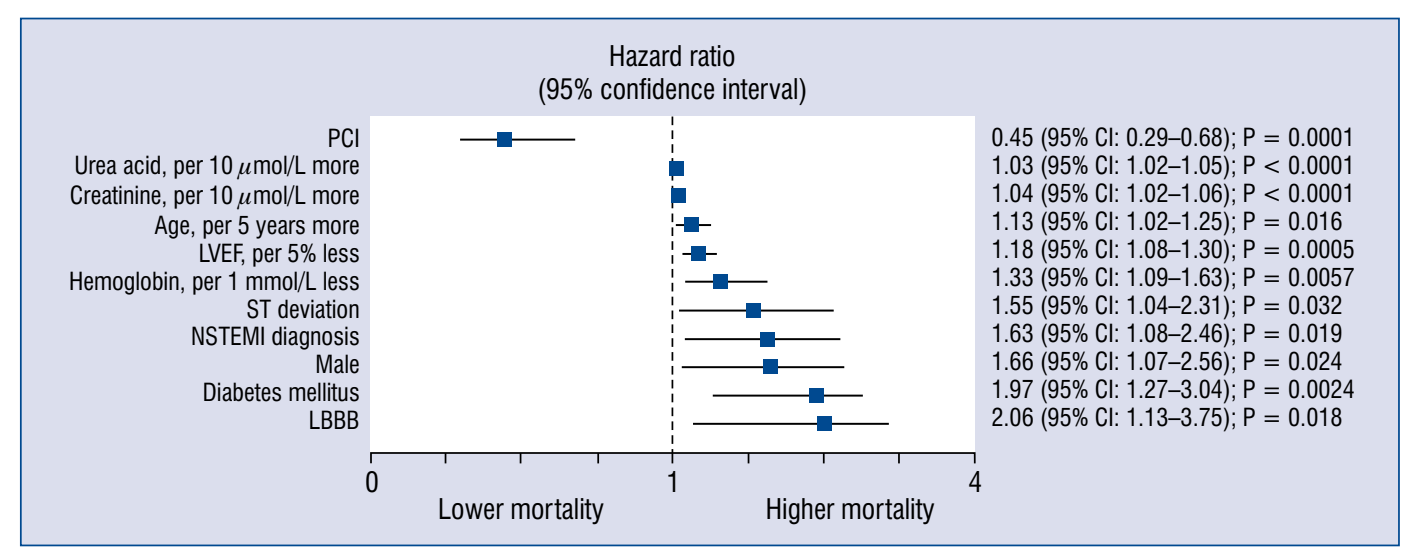

Figure 2. Multivariable analysis of independent predictors of 36-month mortality; LBBB — left bundle branch block; LVEF — left ventricular ejection fraction; NSTEMI - non-ST-segment elevation myocardial infarction; PCl - percutaneous coronary intervention. 
prevalence of multivessel disease was observed in the $2^{\text {nd }}$ quartile $(46 \%)$.

\section{Short-, mid- and long-term outcomes}

Patients with elevated sUA were at significantly higher risk of death during hospitalization, than those with low sUA. No significant difference in the rates of in-hospital TVR and MI should probably be associated with a high procedural success of $\mathrm{PCI}$ and low rate of periprocedural complications. In contrary, high risk of pulmonary edema and cardiogenic shock could at least partly be explained by the significantly worse baseline clinical profile of these patients. Significantly lower LVEF along with much more frequent assignment to the high Killip classes in patients from the higher quartiles should be interpreted as signs of a much more pronounced heart failure (HF). As stated in the literature, patients with NSTE-ACS and HF seem to be more prone to hospitalization complications and have higher in-hospital and 30-day mortality than those without HF [31].

All-cause mortality differed significantly between the analyzed quartiles in both 12 -month and 36 -month follow-up. The relative risk of death in those periods between the $4^{\text {th }}$ and the $1^{\text {st }}$ quartiles was 2.9 and 3.3 , respectively. In the aforementioned study by Ndrepepa et al. [9], 12-month mortality of patients with NSTE-ACS in the $4^{\text {th }}$ and the from $1^{\text {st }}$ to $3^{\text {rd }}$ quartiles of the population were respectively $11.8 \%$ and $4.2 \%$ [9]. One can be surprised that in comparison with the results of the study by Ndrepepa et al. [9], the 1-year mortality of patients from the $4^{\text {th }}$ quartile in the present study was higher despite slightly lower median sUA (352 vs. $373 \mu \mathrm{mol} / \mathrm{L}$ [5.92 vs. $6.27 \mathrm{mg} / \mathrm{dL}])$. The probable explanation is that patients in the current study were more heavily burdened with diabetes $(50.4 \%$ vs. $33.3 \%)$, history of prior MI ( $44.4 \%$ vs. $30.5 \%$ ) and had significantly lower LVEF ( $41.1 \%$ vs. $49.0 \%)$. These differences can potentially explain a higher rate of death observed in the present study.

The giant difference in the prevalence of angiographically proven CTO between the $4^{\text {th }}$ and the $1^{\text {st }}$ quartiles requires additional attention. As it has already been discussed, the number of patients with $\mathrm{HF}$ in the $3^{\text {rd }}$ and $4^{\text {th }}$ quartile was significantly higher than in the lower quartiles. According to the literature, the presence of CTO is an independent risk factor of all-cause death in patients with ACS and concomitant HF [32]. Therefore, almost two-fold higher prevalence of CTO in patients from the $4^{\text {th }}$ quartile than in those from the $1^{\text {st }}$ might be responsible for increased mortality in this subpopulation.

\section{Limitations of the study}

The present study has a few important limitations. One has to be very cautious when drawing straightforward conclusions and suggesting dependences due to the retrospective character of the analysis. Furthermore, the subgroup of patients with NSTE-ACS is very heterogenic, which could potentially result in discrepancies in the outcomes.

Another important limitation of the study is that information on the exact cause of death of all analyzed patients, including the cardiovascular mortality is provided, which is one of the established long-term outcomes in cardiovascular studies and could yield a better characterization of the studied population. Moreover, although the sUA levels were measured from the first blood sample after admission, the information on the exact time from the onset of symptoms to the sUA measurement was not available in all cases, hence one cannot exclude that the variability of sUA in time could influence the results.

Last but not least, the concentration of sUA was not routinely measured in all patients and was not available in 1,379 patients. As the decision on the measurement of sUA was at the discretion of the physician in charge, the results might be slightly biased by the fact that it could have been measured only in patients who had symptoms suggestive of its elevation. Nevertheless, performed herein, is an exploratory analysis comparing the clinical and angiographic characteristics along with outcomes of patients with- and without sUA measurement at baseline (Suppl. Table 1). There were significant differences in the occurrence of 12-month and 36-month death and non-fatal MI between the groups, which suggests that sUA was measured in a population of patients with a significantly higher risk of more dismal long-term outcomes (Suppl. Table 1).

\section{Conclusions}

Elevated baseline sUA concentration in a large single-center cohort was independently associated with worse mid-term and long-term outcomes in patients with NSTE-ACS, however further studies are required to define the mechanism of their association.

Conflict of interest: None declared 


\section{References}

1. Sanchis-Gomar F, Perez-Quilis C, Leischik R, et al. Epidemiology of coronary heart disease and acute coronary syndrome. Ann Transl Med. 2016; 4(13): 256, doi: 10.21037/atm.2016.06.33, indexed in Pubmed: 27500157.

2. Talbott J, Terplan KL. The kidney in gout. Medicine. 1960; 39(4): 469-526, doi: 10.1097/00005792-196012000-00001.

3. Klinenberg JR, Kippen I, Bluestone R. Hyperuricemic nephropathy: pathologic features and factors influencing urate deposition. Nephron. 1975; 14(1): 88-98, doi: 10.1159/000180438, indexed in Pubmed: 235747.

4. Corry DB, Eslami P, Yamamoto K, et al. Uric acid stimulates vascular smooth muscle cell proliferation and oxidative stress via the vascular renin-angiotensin system. J Hypertens. 2008; 26(2): 269-275, doi: 10.1097/HJH.0b013e3282f240bf, indexed in Pubmed: 18192841.

5. Kang DH, Park SK, Lee IK, et al. Uric acid-induced C-reactive protein expression: implication on cell proliferation and nitric oxide production of human vascular cells. J Am Soc Nephrol. 2005; 16(12): 3553-3562, doi: 10.1681/ASN.2005050572, indexed in Pubmed: 16251237.

6. Khosla UM, Zharikov S, Finch JL, et al. Hyperuricemia induces endothelial dysfunction. Kidney Int. 2005; 67(5): 1739-1742, doi: 10.1111/j.1523-1755.2005.00273.x, indexed in Pubmed: 15840020 .

7. Kowalczyk J, Francuz P, Swoboda R, et al. rognostic significance of hyperuricaemia in patients with different types of renal dysfunction and acute myocardial infarction treated with percutaneous coronary intervention. Nephron Clin Pract. 2010; 116: 114-122.

8. Pagidipati NJ, Hess CN, Clare RM, et al. An examination of the relationship between serum uric acid level, a clinical history of gout, and cardiovascular outcomes among patients with acute coronary syndrome. Am Heart J. 2017; 187: 53-61, doi: 10.1016/j.ahj.2017.02.023, indexed in Pubmed: 28454808.

9. Ndrepepa G, Braun S, Haase HU, et al. Prognostic value of uric acid in patients with acute coronary syndromes. Am J Cardiol. 2012; 109(9): 1260-1265, doi: 10.1016/j.amjcard.2011.12.018, indexed in Pubmed: 22325088.

10. Magnoni M, Berteotti M, Ceriotti F, et al. Serum uric acid on admission predicts in-hospital mortality in patients with acute coronary syndrome. Int J Cardiol. 2017; 240: 25-29, doi: 10.1016/j. ijcard.2017.04.027, indexed in Pubmed: 28476518.

11. Lazzeri C, Valente S, Chiostri M, et al. Uric acid in the acute phase of ST elevation myocardial infarction submitted to primary PCI: its prognostic role and relation with inflammatory markers: a single center experience. Int J Cardiol. 2010; 138(2): 206-209, doi: 10.1016/j.ijcard.2008.06.024, indexed in Pubmed: 18684529.

12. He C, Lin P, Liu W, et al. Prognostic value of hyperuricemia in patients with acute coronary syndrome: a meta-analysis. Eur J Clin Invest. 2019; 49(4): e13074, doi: 10.1111/eci.13074, indexed in Pubmed: 30701529.

13. Bassand JP, Hamm CW, Ardissino D, et al. Guidelines for the diagnosis and treatment of non-ST-segment elevation acute coronary syndromes. Eur Heart J. 2007; 28(13): 1598-1660, doi: 10.1093/eurheartj/ehm161, indexed in Pubmed: 17569677.

14. Hamm CW, Bassand JP, Agewall S, et al. ESC Guidelines for the management of acute coronary syndromes in patients presenting without persistent ST-segment elevation: The Task Force for the management of acute coronary syndromes (ACS) in pa- tients presenting without persistent ST-segment elevation of the European Society of Cardiology (ESC). Eur Heart J. 2011; 32: 2999-3054.

15. Roffi M, Patrono C, Collet JP, et al. 2015 ESC Guidelines for the management of acute coronary syndromes in patients presenting without persistent ST-segment elevation. Eur Heart J. 2015; 37(3): 267-315, doi: 10.1093/eurheartj/ehv320.

16. Thygesen K, Alpert JS, Jaffe AS, et al. et al.. Third universal definition of myocardial infarction. Eur Heart J. 2012; 33: 2551-2567.

17. Quinn TJ, Paolucci S, Sunnerhagen KS, et al. European Stroke Organisation (ESO) Executive Committee, ESO Writing Committee, European Stroke Organisation (ESO) Executive Committee, ESO Writing Committee. Guidelines for management of ischaemic stroke and transient ischaemic attack 2008. Cerebrovasc Dis. 2008; 25(5): 457-507, doi: 10.1159/000131083, indexed in Pubmed: 18477843.

18. Agabiti-Rosei E, Grassi G. Beyond gout: uric acid and cardiovascular diseases. Curr Med Res Opin. 2013; 29 Suppl 3: 33-39, doi: 10.1185/03007995.2013.790804, indexed in Pubmed: 23611366.

19. Jossa F, Farinaro E, Panico S, et al. Serum uric acid and hypertension: the Olivetti heart study. J Hum Hypertens. 1994; 8(9): 677-681, indexed in Pubmed: 7807497.

20. Dehghan A, van Hoek M, Sijbrands EJG, et al. High serum uric acid as a novel risk factor for type 2 diabetes. Diabetes Care. 2008; 31(2): 361-362, doi: 10.2337/dc07-1276, indexed in Pubmed: 17977935.

21. Yoo TW, Sung KiC, Shin HS, et al. Relationship between serum uric acid concentration and insulin resistance and metabolic syndrome. Circ J. 2005; 69(8): 928-933, doi: 10.1253/circj.69.928, indexed in Pubmed: 16041161.

22. Ndrepepa G, Braun S, King L, et al. Uric acid and prognosis in angiography-proven coronary artery disease. Eur J Clin Invest. 2013; 43(3): 256-266, doi: 10.1111/eci.12039, indexed in Pubmed: 23278454.

23. Saito Y, Nakayama T, Sugimoto K, et al. Relation of lipid content of coronary plaque to level of serum uric acid. Am J Cardiol. 2015; 116(9): 1346-1350, doi: 10.1016/j.amjcard.2015.07.059, indexed in Pubmed: 26381534.

24. Biscaglia S, Ceconi C, Malagù M, et al. Uric acid and coronary artery disease: An elusive link deserving further attention. Int J Cardiol. 2016; 213: 28-32, doi: 10.1016/j.ijcard.2015.08.086, indexed in Pubmed: 26318389.

25. Khosla UM, Zharikov S, Finch JL, et al. Hyperuricemia induces endothelial dysfunction. Kidney Int. 2005; 67(5): 1739-1742, doi: 10.1111/j.1523-1755.2005.00273.x, indexed in Pubmed: 15840020 .

26. Kobayashi N, Asai K, Tsurumi M, et al. Impact of accumulated serum uric acid on coronary culprit lesion morphology determined by optical coherence tomography and cardiac outcomes in patients with acute coronary syndrome. Cardiology. 2018; 141(4): 190-198, doi: 10.1159/000496053, indexed in Pubmed: 30759435.

27. Kobayashi N, Hata N, Tsurumi M, et al. Relation of coronary culprit lesion morphology determined by optical coherence tomography and cardiac outcomes to serum uric acid levels in patients with acute coronary syndrome. Am J Cardiol. 2018; 122(1): 17-25, doi: 10.1016/j.amjcard.2018.03.022, indexed in Pubmed: 29678337.

28. Ando K, Takahashi $\mathrm{H}$, Watanabe $\mathrm{T}$, et al. Impact of serum uric acid levels on coronary plaque stability evaluated using integrat- 
ed backscatter intravascular ultrasound in patients with coronary artery disease. J Atheroscler Thromb. 2016; 23(8): 932-939, doi: 10.5551/jat.33951, indexed in Pubmed: 26947600.

29. Zhang D, Zhang R, Wang N, et al. Correlation of serum uric acid levels with nonculprit plaque instability in patients with acute coronary syndromes: a 3-vessel optical coherence tomography study. Biomed Res Int. 2018; 2018: 7919165, doi: 10.1155/2018/7919165, indexed in Pubmed: 29568764.

30. Kojima S, Sakamoto T, Ishihara M, et al. Prognostic usefulness of serum uric acid after acute myocardial infarction (the Japanese Acute Coronary Syndrome Study). Am J Cardiol. 2005;
96(4): 489-495, doi: 10.1016/j.amjcard.2005.04.007, indexed in Pubmed: 16098298 .

31. Bahit MC, Lopes RD, Clare RM, et al. Heart failure complicating non-ST-segment elevation acute coronary syndrome: timing, predictors, and clinical outcomes. JACC Heart Fail. 2013; 1(3): 223-229, doi: 10.1016/j.jchf.2013.02.007, indexed in Pubmed: 24621874.

32. Tajstra M, Pyka $€$, Gorol J, et al. Impact of chronic total occlusion of the coronary artery on long-term prognosis in patients with ischemic systolic heart failure: insights from the COMMIT-HF registry. JACC Cardiovasc Interv. 2016; 9(17): 1790-1797, doi: 10.1016/j.jcin.2016.06.007, indexed in Pubmed: 27609252. 